\section{Estudos hematológicos em Oreochromis niloticus (Linnaeus, 1758) (Cichlidae, Teleostei) - Parte I}

\author{
Hematological studies in Oreochromis niloticus (Linnaeus, 1758) \\ (Cichlidae, Teleostei) - Part I
}

Ivete Kotomi UEDA'; Mizue Imoto EGAMI'; Wilson da Silva SASSO'; Eliana Reiko MATUSHIMA ${ }^{2}$

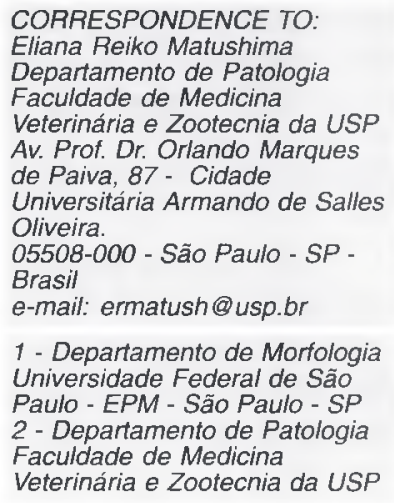

\title{
RESUMO
}

Avaliou-se o hemograma e a morfologia celular em amostras de sangue periférico obtidas de 10 peixes da espécie Oreochromis niloticus. Parte das mesmas foi utilizada para o estudo da hematimetria, isto é, contagem de eritrócitos $\left(\bar{x}=2,35 \times 10^{6} / \mathrm{mm}^{3}\right.$ $\pm 0,12)$, taxa de hemoglobina, $(\bar{x}=7,04 \mathrm{~g} / \mathrm{dL} \pm 0,38)$, hematócrito $(\bar{x}=27,85 \% \pm 1,62), \mathrm{HCM}(\bar{x}=30,31 \mathrm{pg} \pm 1,64), \mathrm{VCM}(\bar{x}=$ $\left.118,6 \mu^{3} \pm 3,53\right), \mathrm{CHCM}(\bar{x}=25,78 \% \pm 1,72)$, contagem global de leucócitos $\left(\bar{x}=16,08 \times 10^{3} / \mathrm{mm}^{3} \pm 1,28\right), \mathrm{contagem} \mathrm{de}$ trombócitos $\left(\bar{x}=61,69 \times 10^{3} / \mathrm{mm}^{3} \pm 5,96\right)$, sendo a avaliação da morfologia das células do sangue reallizada através do estudo de extensões sangüíneas submetidas à coloração de Wright. Os eritrócitos e trombócitos nucleados apresentaramse elípticos; neutrófilos e eosinófilos esféricos de tamanho variável, com o núcleo também esférico, apresentaram citoplasmas abundantes, ligeiramente basófilo e altamente acidófilo, respectivamente. Não foram vistas as formas polimorfonucleares dessas células. Os basófilos apresentaram núcleo esférico e granulações metacromáticas. Os monócitos e os linfócitos assemelharam-se morfologicamente aos dos mamíferos.

\section{UNITERMOS: Sangue; Morfologia; Hematologia; Oreochromis niloticus; Peixes.}

\section{INTRODUÇÃO}

$\mathrm{O}$ interesse pelos peixes como animais de laboratórios tem aumentado de maneira considerável nas últimas décadas. Inúmeros trabalhos têm sido publicados, abordando a sua fïsiologia, bioquímical, patologia (Houston et al. ${ }^{13}, 1971$, Fletcher"1. 1975, Matushima", 1988 e Nakamoto et al. ${ }^{20}, 1992$ ), ou mesmo os aspectos imunocitoquímicos (Koumans-van-Diepen et al. ${ }^{17}, 1994$ ). No que se relere à hemato-ictiologia propriamente dita, devem ser destaciados os trabalhos de Oria” (1932), Phillips Jr. ${ }^{2.3}$ (1940) e Black et al.? (1966) como pioneiros, ao estabelecerem comparação do quadro hematológico entre as diversas espécies. Nas décadas subseqüentes, inúmeras investigações foram realizadas para estabelecer os valores do hemograma dos peixes teleósteos (Catton', 1951, Jakowska ${ }^{1.5}, 1956$ e Ezzalt et al $^{8}, 1974$ ). Assim, quanto ao estudo das células de linhagem eritrocítica, citam-se as publicações de Badawi: Said (1971), Blaxhall; Daisley ${ }^{3}$ (1973), Ezzat et al ${ }^{8}$ (1974) e Imagawa ef al. ${ }^{1+}(1989)$, ressaltando-se outros autores que se preocuparam com o estudo da morfologia dos eritrócitos (Catton 5 , 1951, Ribeiro ${ }^{25}, 1978$ e Imagawa et al. ${ }^{14}, 1989$ ). No que se refere à determinação dos índices hematimétricos absolutos, pode-se citar os trabalhos de Ribeiro ${ }^{25}$ (1978) e Oladimeji et al..$^{21}$ (1988). Em relação aos trombócitos, Ribeiro ${ }^{25}$ ( 1978 ) e Imagawa et al. ${ }^{14}$ ( 1989 ) descreveram variações quanto ao número e à morfologia dos mesmos. Por outro lado, alguns autores demonstraram interesse especial no estudo dos leucócitos envolvendo os mais variados aspectos (Srivastava ${ }^{26}$, 1968, Blaxhall; Daisley ${ }^{3}, 1973$, Ezzat et al. ${ }^{8}, 1974$, Ellis $^{7}$. 1976. Ferguson ${ }^{10}, 1976$, Boomker ${ }^{4}, 1981$, Doggett; Harris ${ }^{6}$, 1989 e Imagawa ef $a l^{1+}, 1989$ ). Em face do exposto e consideran- do-se que, em relação ao estudo hematológico propriamente dito. especificamente da espécie Oreochromis niloticus, a literatura é escassa, este trabalho tem por objetivo estudar, nessa espécie de teleósteo, os aspectos morfológicos das células sangiiíneas, bem como estabelecer os valores dos diferentes componentes do hemograma do sangue periférico.

\section{MATERIAL E MÉTODO}

Foram utilizados 10 espécimes de Oreochromis niloticus. ciclídeo, de água doce, da classe dos teleósteos, sem levar em consideração o sexo, mantidos em tanques aerados com bombas compressoras, à temperatura ambiente, provenientes do Departamento de Patologia da Faculdade de Medicina Veterinária e Zootecnia da Universidade de São Paulo. O peso desses animais variou de $135 \mathrm{~g}$ a $370 \mathrm{~g}$ e o comprimento total de $20,0 \mathrm{~cm}$ a $27,5 \mathrm{~cm}$. Para o estudo morfológico e hematimétrico de Oreochromis niloticus, $2 \mathrm{ml}$ de sangue foram colhidos por punção da veia caudal, na presença de anticoagulante EDTA, após a anestesia com benzocaína na concentração de $1 / 10.000 \mathrm{em}$ água de torneira. As amostras de sangue foram colhidas no período de dezembro a março de 1990 , isto é, durante o verão, quando a temperatura da água foi mantida ao redor de $20^{\circ} \mathrm{C}$. Foram realizadas três extensões sanguíneas de cada peixe, submetidas à coloração pelo método de Wright e utilizadas para a contagem diferencial e descrição morfológica de eritrócitos, leucócitos e trombócitos. Foram contados 100 leucócitos de cada extensão, totalizando-se 300 células para cada animal, o que possibilitou a obtenção da média da contagem diferencial de leucócitos de cada peixe. 
Para a contagem total de células sanguíneas, tanto de eritrócitos quanto de leucócitos, foi empregada a câmara de Neubauer utilizando-se como diluidores respectivamente os líquidos de Hayen (Hendricks ${ }^{12}$, 1952) e de Shaw (Srivastava ${ }^{26}, 1968$ ). Na determinação do volume globular ou hematócrito, utilizou-se o método do micro-hematócrito a 12.000 r.p.m. (Quentel; Obach ${ }^{24}$, 1992). A dosagem de hemoglobina foi efetuada com o uso do mé1odo de cianometa-hemoglobina (Facchini", 1987). A partir dos valores de contagem de eritrócitos, porcentagem de hematócrito e vaIor da taxa de hemoglobina, foram calculados os valores dos índices hematimétricos absolutos (Jannini; Jannini Filho'th, 1978), ou seja, do Volume Corpuscular Médio (VCM), Hemoglobina Corpuscular Média (HCM) e Concentração Hemoglobínica Corpuscular Média (CHCM). Para a contagem de trombócitos, foi utilizado o método indireto, conlorme descrito por Imagawa ef $a l^{14}$ (1989).

O critério de escolha para a nomenclatura das células sanguíneas dos peixes estudados foi baseado no aspecto morfológico do núcleo, padrão de distribuição dos grânulos, bem como nos aspectos tintoriais. Para classificar os diferentes tipos de leucócitos seguiu-se a nomenclatura adotada por Ezzat el al. ${ }^{.}$(1974), porque as descrições morfológicas apresentadas por esses autores são mais adaptáveis ao material usado nesta pesquisa. Imagawa et al. ${ }^{14}$ ( 1989$)$ relataram que ainda não foram bem padronizados os critérios para a classificação e nomenclatura das células sangüíneas dos peixes. em razão das dúvidas sobre a morfologia precisa relacionada aos trombócitos e linfócitos.

\section{RESULTADOS}

O número global de eritrócitos de (Oreochromis niloticus vatriou ao redor de $2,35 \times 10^{6} / \mathrm{mm}^{3}$ (Tab. I). A dosagem de hemoglobina e a determinação do valor do hematócrito mostraram, respectivamente, valores médios de: 7,(04 g/dL $\pm 0,38$ e 27,85\% 1,62 (Tab.1). No que se refere aos índices hematimétricos absolutos, foram obtidos os seguintes valores médios: VCM $-118,6 \mu^{3} \pm 3.53$; $\mathrm{HCM}-$ $30,31 \mathrm{pg} \pm 1,64 ; \mathrm{e} \mathrm{CHCM}-25,78 \% \pm 1.72$ (Tab. I).

Com relação às observações dos elementos figurados do sangue periférico de Oreochromis niloticus pode-se identificar as

\section{Tabela 1}

Contagem de eritrócitos, dosagem de hemoglobina, determinação do hematócrito e índices hematimétricos absolutos do sangue periférico de Oreochromis niloticus (São Paulo, 1990).

\begin{tabular}{ccccccc}
\hline PEIXE & $\begin{array}{c}\text { ERIT } \\
\left(\times 10^{6} / \mathrm{mm}^{3}\right)\end{array}$ & $\begin{array}{c}\mathrm{HB} \\
(\mathrm{g} / \mathrm{dL})\end{array}$ & $\begin{array}{c}\mathrm{HTC} \\
(\%)\end{array}$ & $\begin{array}{c}\text { VCM } \\
\left(\mu^{3}\right)\end{array}$ & $\begin{array}{c}\text { HCM } \\
(\mathrm{pg})\end{array}$ & $\begin{array}{c}\mathrm{CHCM} \\
(\%)\end{array}$ \\
\hline 1 & 1,88 & 6,7 & 20,0 & 106 & 35,6 & 33,5 \\
2 & 2,22 & 7,1 & 27,0 & 122 & 32,0 & 26,3 \\
3 & 3,08 & 8,0 & 35,0 & 114 & 26,0 & 22,8 \\
4 & 2,22 & 5,1 & 26,0 & 117 & 23,0 & 19,6 \\
5 & 2,07 & 6,3 & 28,0 & 135 & 30,4 & 22,5 \\
6 & 2,88 & 7,4 & 33,0 & 114 & 25,7 & 22,4 \\
7 & 2,28 & 6,0 & 26,0 & 114 & 26,3 & 23,1 \\
8 & 2,02 & 6,3 & 23,0 & 114 & 31,2 & 27,4 \\
9 & 2,52 & 8,3 & 35,5 & 141 & 32,9 & 23,4 \\
10 & 2,30 & 9,2 & 25,0 & 109 & 40,0 & 36,8 \\
$\overline{\mathbf{x}} \pm \mathrm{S} \overline{\mathbf{x}}$ & $2,35 \pm 0,12$ & $7,04 \pm 0,38$ & $27,85 \pm 1,62$ & $118,6 \pm 3,53$ & $30,31 \pm 1,64$ & $25,78 \pm 1,72$
\end{tabular}

ERIT = Eritrócito; $\mathrm{HB}=$ Hemoglobina; $\mathrm{HTC}=$ Hematócrito; $\mathrm{VCM}=$ Volume Corpuscular Médio; $\mathrm{HCM}=$ Hemoglobina Corpuscular Média; $\mathrm{CHCM}=$ Concentração de Hemoglobina Corpuscular Média.

Tabela 2

Contagens total e diferencial de leucócitos e de trombócitos do sangue periférico de Oreochromis niloticus (São Paulo, 1990)

\begin{tabular}{|c|c|c|c|c|c|c|c|c|c|c|c|c|}
\hline \multirow{2}{*}{\multicolumn{2}{|c|}{$\begin{array}{l}\text { PEIXE LEUC } \\
\left(\times 10^{3} / \mathrm{mm}^{3}\right) \\
\end{array}$}} & \multicolumn{2}{|c|}{ NEUT } & \multicolumn{2}{|c|}{ EOS } & \multicolumn{2}{|c|}{ BASÓ } & \multicolumn{2}{|c|}{ LINF } & \multicolumn{2}{|c|}{ MONÓ } & \multirow{2}{*}{$\begin{array}{l}\text { TROMB } \\
\left(\times 10^{3} / \mathrm{mm}^{3}\right)\end{array}$} \\
\hline & & 3) $\left(/ \mathrm{mm}^{3}\right)$ & $(\%)$ & $\left(/ \mathrm{mm}^{3}\right)$ & $(\%)$ & $\left(/ \mathrm{mm}^{3}\right)$ & $(\%)$ & $\left(/ \mathrm{mm}^{3}\right)$ & $(\%)$ & $\left(/ \mathrm{mm}^{3}\right)$ & $(\%)$ & \\
\hline 1 & 7,30 & 3073,3 & 42,1 & 7,3 & 0,1 & 7,3 & 0,1 & 4022,3 & 55,1 & 189,8 & 2,6 & 38,54 \\
\hline 2 & 13,53 & 5939,7 & 43,9 & 0,0 & 0,0 & 0,0 & 0,0 & 6940,9 & 51,3 & 649,4 & 4,8 & 63,71 \\
\hline 3 & 14,80 & 7622,0 & 51,5 & 14,8 & 0,1 & 0,0 & 0,0 & 6171,6 & 41,7 & 991,6 & 6,7 & 77,62 \\
\hline 4 & 17,53 & 10062,2 & 57,4 & 0,0 & 0,0 & 35,1 & 0,2 & 6118,0 & 34,9 & 1314,7 & 7,5 & 71,48 \\
\hline 5 & 14,60 & 5883,8 & 40,3 & 0,0 & 0,0 & 0,0 & 0,0 & 8292,8 & 56,8 & 423,4 & 2,9 & 54,85 \\
\hline 6 & 18,87 & 10925,8 & 57,9 & 0,0 & 0,0 & 37,7 & 0,2 & 6736,6 & 35,7 & 1169,9 & 6,2 & 100,80 \\
\hline 7 & 17,53 & 10202,5 & 58,2 & 0,0 & 0,0 & 17,5 & 0,1 & 6205,6 & 35,4 & 1104,4 & 6,3 & 68,86 \\
\hline 8 & 20,20 & 10463,6 & 51,8 & 40,4 & 0,2 & 40,4 & 0,2 & 7474,0 & 37,0 & 2181,6 & 10,8 & 42,62 \\
\hline 9 & 14,93 & 7181,3 & 48,1 & 0,0 & 0,0 & 0,0 & 0,0 & 6882,7 & 46,1 & 866,0 & 5,8 & 49,64 \\
\hline 10 & 21,47 & 10649,1 & 49,6 & 0,0 & 0,0 & 21,5 & 0,1 & 8630,9 & 40,2 & 2168,5 & 10,1 & 48,76 \\
\hline $\bar{x}$ & 16,08 & 8200,33 & 50,08 & 6,25 & 0,04 & 15,95 & 0,09 & 6747,54 & 43,42 & 1105,93 & 6,37 & 61,69 \\
\hline$S \bar{x}$ & $\pm 1,28$ & $\pm 844,92$ & & $\pm 4,10$ & & $\pm 5,34$ & & $\pm 408,09$ & & $\pm 208,79$ & & $\pm 5,96$ \\
\hline
\end{tabular}

LEUC = Leucócito; NEUT = Neutrófilo; EOS = Eosinófilo; BASÓ = Basófilo; LINF $=$ Linfócito; MONÓ = Monócito; TROMB = Trombócito. 


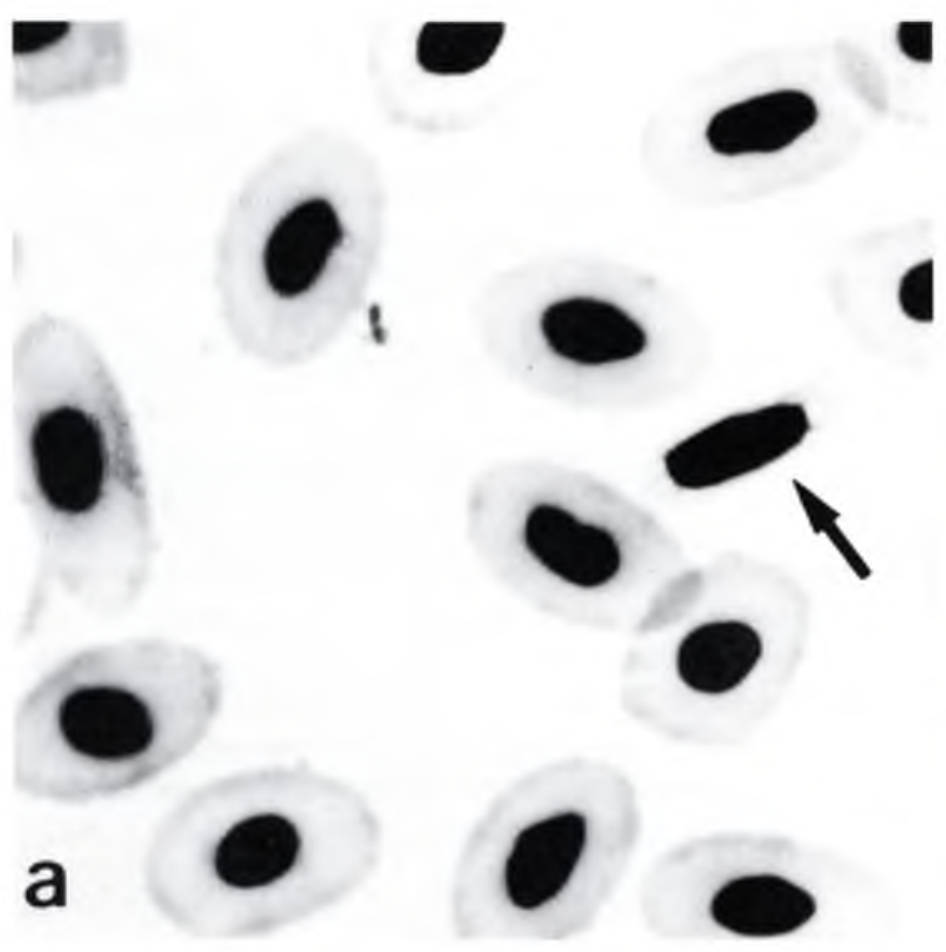

Figura 1a

Fotomicrografia da extensão do sangue periférico de Oreochromis niloticus. Eritrócitos ao redor de um trombócito eliptico (seta). Método de Wright. Oc. 10x Obj.100x.

seguintes células: eritrócitos, trombócitos, neutrófilos, eosinófilos, basófilos, linfócitos e monócitos. O valor médio do número total de leucócitos encontrado em Orechromis niloticus foi de $16,08 \times 10^{3} / \mathrm{mm}^{3} \pm 1,28$ (Tab. 2 ). A contagem diferencial dos leucócitos demonstrou a predominância dos neutrófilos $(8200,33$ / $\left.\mathrm{mm}^{3} \pm 844,92\right)$ e seguidos numericamente por menor valor de linfócitos $\left(6747,54 / \mathrm{mm}^{3} \pm 408,09\right)$ (Tab.2). Os valores médios de monócitos, eosinófilos e basófilos foram de $1105,93 / \mathrm{mm}^{3} \pm 208,79$; $6,25 / \mathrm{mm}^{3} \pm 4,10$ e $15,95 / \mathrm{mm}^{3} \pm 5,34$, respectivamente (Tab.2). Em relação ao número de trombócitos, o valor médio encontrado em Orechromis niloticus foi de $61.69 \times 10 \% / \mathrm{mm}^{3} \pm 5,96$ (Tab.2). Tendo discretas variações na dimensão, a forma predominante de eritrócito encontrada em Orechromis niloticus foi a elíptica, com o núcleo também elíptico e local izado centralmente, sendo a heterocromatina corada em violeta e o citoplasma acidófilo (Fig. Ia).

No que se refere aos neutrófilos, os mesmos apresentavamse esféricos e de tamanho variável; o citoplasma era abundante e ligeiramente basófilo, mostrando escassos grânulos azurófilos. $\mathrm{O}$ núcleo esférico era pequeno, corado em violeta e geralmente localizado excentricamente (Fig.lb). Os eosinófilos de Orecohromis niloticus eram vistos sob a forma esférica, de tamanho variável, citoplasma abundante e preenchido homogeneamente por grânulos acidófilos grandes e de tamanho variável. A heterocromatina de cor violeta ocupava todo o núcleo que, geralmente, estava situado em posição central e, eventualmente, em posição excêntrica. Os basófilos eram esféricos, com citoplasma rico em granulações fortemente basófilas, de tamanho variável e corados metacromaticamente. O núcleo era esférico e corado em violeta. Às vezes, não foi possível distinguir o contorno nuclear em virtude da presença desses grânuIos. Os linfócitos esféricos e de tamanho variável, com citoplasma escasso e ligeiramente basófilo, apresentavam, com frequiência, pro-

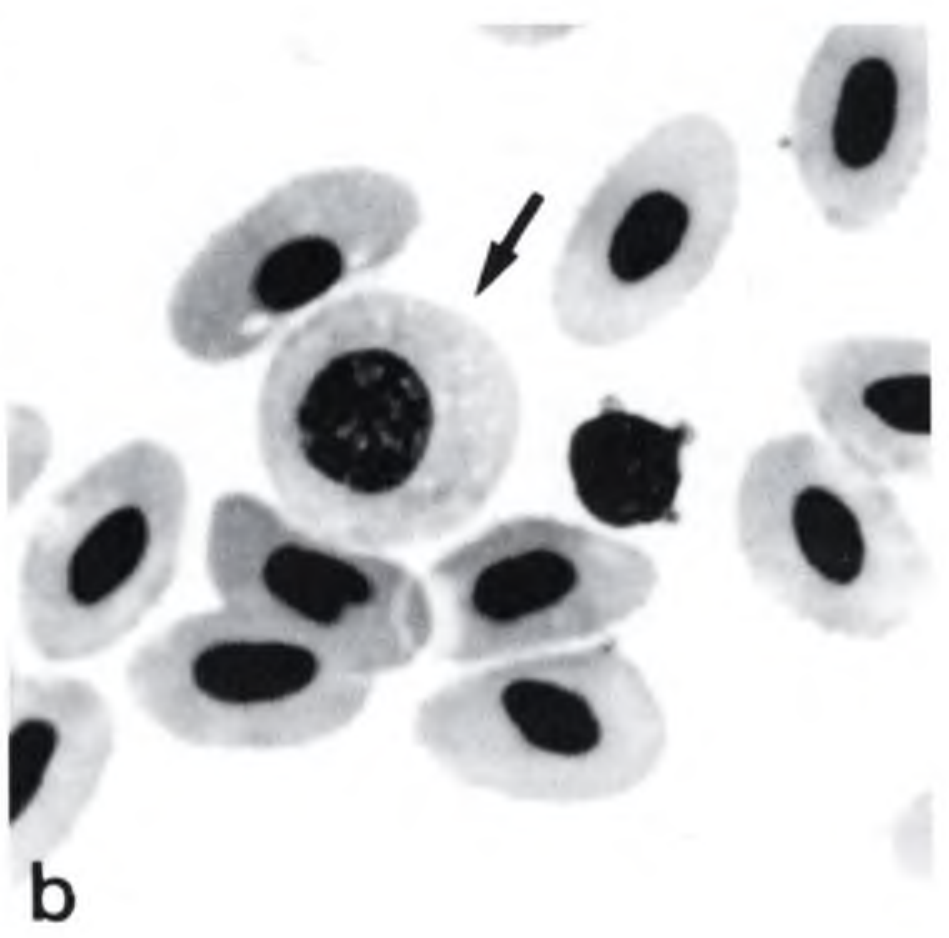

Figura 1b

Fotomicrografia da extensão do sangue periférico de Oreochromis niloricus. Eritrócitos ao redor de um leucócito do tipo neutrófilo, em posição central (seta), ao lado de um linfócito. Método de Wright. Oc. 10x. Obj. 100x.
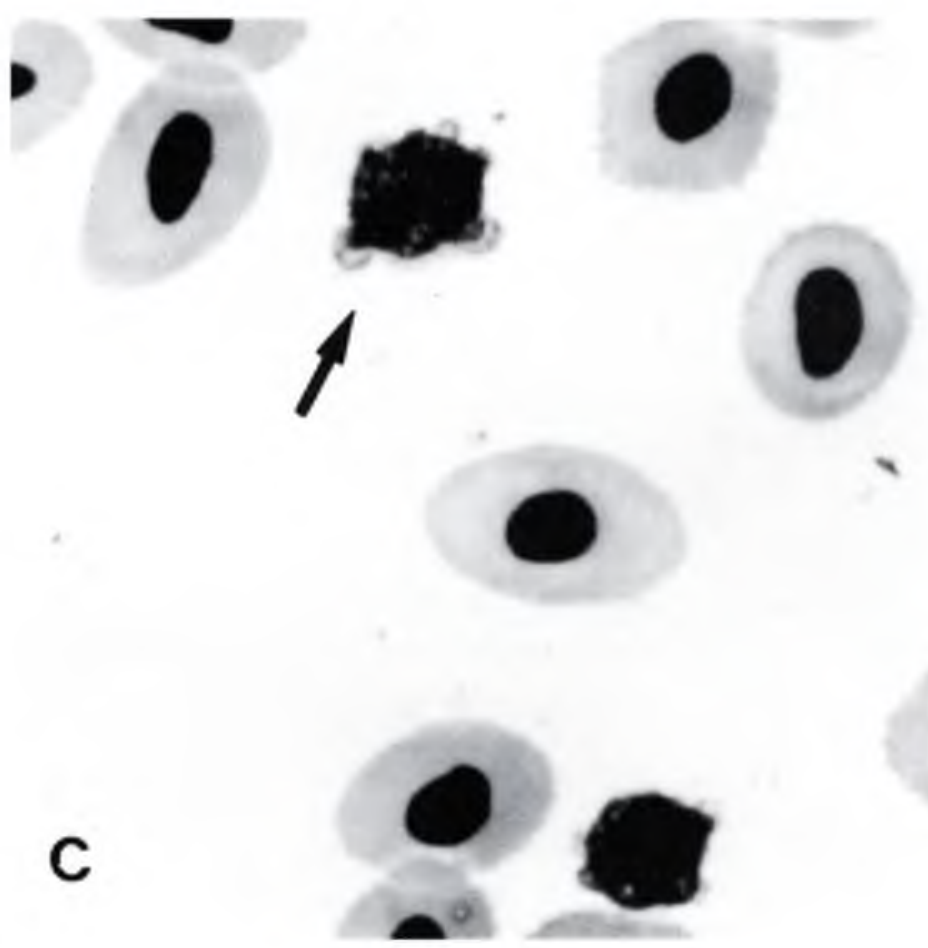

Figura 1c

Fotomicrografia da extensão do sangue peritérico de Oreochromis niloticus. Leucócito do tipo linfócito (seta), circundado por eritrócitos.

Método de Wright. Oc. 10x. Obj. 100x. 
UEDA. I.K.: EGAMI, M.I.: SASSO. W.S.; MATUSIHIMA. E.R. Estudos hematológicos em Oreochomis niloticus (Linnaeus, 1758) (Cichlidae, Teleostei) - Parte I. Braz. .J. vet. Res. anim. Sci., São Paulo, v. 34, n. 5, p. 270-275, 1997
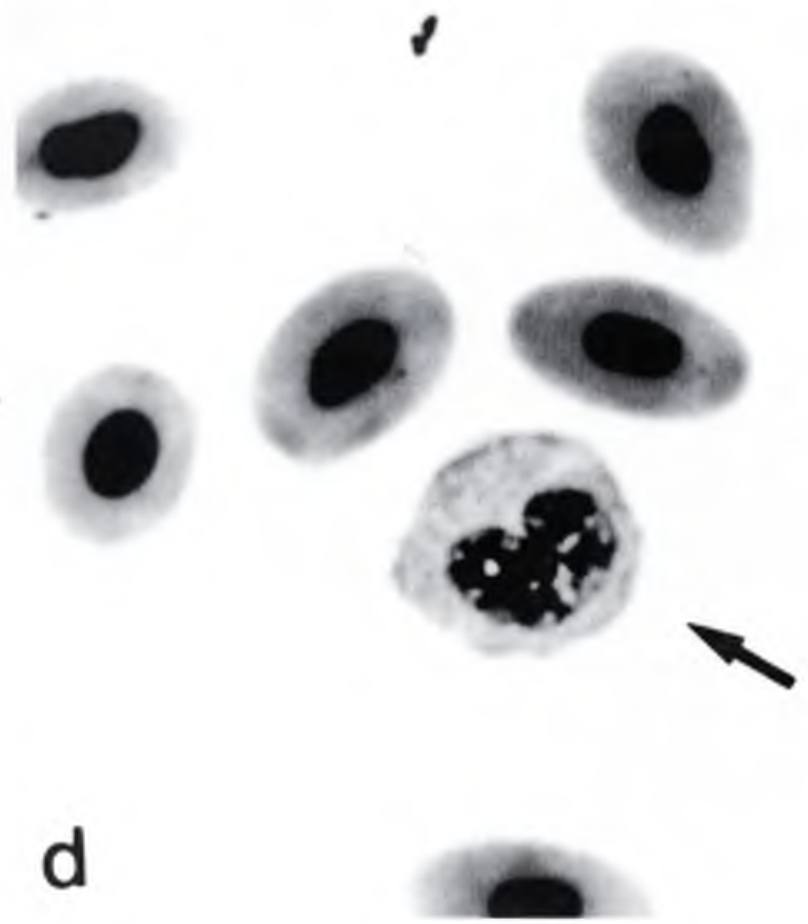

Figura 1d

Fotomicrografia da extensāo do sangue periférico de Oreochromis niloticus. Eritrócitos ao redor de um leucócito do tipo monócito (seta). Método de Wright. Oc. 10x. Obj. 100x

jeções citoplasmáticas denominadas "blebs", bem como a presença de raros grânulos azurófílos. O núcleo era esférico, corado em violeta, ocupando quase toda a superfície da célula (Fig. Ic). Os monócitos eram predominantemente esféricos e com contorno irregular. O citoplasma era abundante e basófilo, com alguns grânulos azurófilos e, eventualmente. havia a presença de vacúolos. O núcleo de coloração violeta cra rico em eucromatina, grande e chanfrado. podendo ser esférico e situado excentricamente (Fig. Id). Os trombócitos eram elípticos, com núcleo também elíptico e localizado centralmente; a heterocromatina corava-se em violeta, sendo o citoplasma ligeiramente acidófilo com pequenas áreas arredondadas e claras nas extremidades (Fig. Ia). Ocasionalmente foram encontradas formas esféricas.

\section{DISCUSSÃO}

O estudo morfológico das células sanguíneas demonstrou que, com discrelas variações na dimensão, a forma predominante de eritrócito encontrada em Oreochromis niloticus foi a elíptica, correspondente àquela observada por Imagawa et al. ${ }^{14}$ ( 1989 ) para Cyprinus carpio. O valor médio do número de eritrócitos obtido em Oreochromis niloticus está muito próximo ao constatado por Ribeiro ${ }^{25}$ ( 1978 ) para Pimelodus maculatus, porém mostrou-se superior alos valores relatados em Tilapia galilaea por Badawi; Said' (1971). A concentração de hemoglobina de Oreochromis niloticus corresponde aquela de Salmo trutha (Blaxhall; Daisley ${ }^{3}, 1973$ ). Em relação ao valor do hematócrito, as médias estão muito próximas daquelas de Tilapia zilli e Tilapia aurea (Badawi; Said', 1971).
Quanto aos índices hematimétricos absolutos, os valores médios obtidos em Oreochromis niloticus diferem daqueles relatados por Ribeiro ${ }^{25}$ (1978) em Pimelodus maculatus e por Oladimeji et al. ${ }^{21}(1988)$ em Oreochromis niloticus. Possivelmente essas diferenças de resultados estariam relacionadas principalmente aos fatores tamanho e peso dos peixes (diferentes espécies) e à metodologia utilizada.

É referido na literatura que os valores de leucócitos podem variar muito entre os peixes da mesma espécie ou entre espécies diferentes. O valor médio do número total de leucócitos encontrado em Oreochromis niloticus assemelhase ao demonstrado por Imagawa et al. ${ }^{14}$ (1989) em Cyprimus carpio. Na contagem diferencial de leucócitos registrou-se a predominância de neutrólilos, com valor que confirma aquele relatado por Boomker ${ }^{+}$(1981) em Sarolherodon mossambicus. Segue-se em magnitude numérica o valor de linfócitos, o que difere das achados de Blaxhall; Daisley (1973) em Salmo trulla. os quais referem a predominância de linfócitos, com valor ao redor de $85 \%$. Alguns autores realizaram contagem diferencial de leucócitos em peixes, considerando o tamanho dos espécimes e a variação sazonal. Assim. Ezzat et al. ${ }^{8}$ (1974), em Tilapia zilli, relataram que o número de neutrófilos é diretamente proporcional ao tamanho desses peixes; e quanto à variação sazonal, os mesmos obtiveram menor porcentagem de neutrófilos no período correspondente à época de clima frio, razão pela qual as amostras foram colhidas na época de verão.

Os neutrófilos de Oreochromis niloticus apresentaramse esféricos e de tamanho variável, com citoplasma abundante e ligeiramente basófilo, apresentando escassos grânulos azurófilos, descrição que corresponde àquela relatada em Tilapia zilli por Ezzat et $a l^{8}$ (1974). A morfologia verificada para os eosinófilos de Oreochromis niloticus assemelha-se àquela encontrada por Ezzat et al. ${ }^{8}$ (1974) em Tilapia zilli, e o número absoluto e o percentual deste tipo celular demonstrado nesta pesquisa são concordantes com aqueles encontrados por Martins: Pitombeira'8 (1968) em Opisthonema oglinum. Os basófilos apresentaram-se esféricos, com citoplasma rico em granulações fortemente basófilas de tamanho variável e coradas metacromaticamente, correspondendo tal descrição à demonstrada por Ezzat et al. ${ }^{8}$ (1974) em Tilapia zilli. Quanto ao número de basófilos, deve ser ressaltado que é semelhante ao constatado por Boomker (1981) em Sarotherodon mossambicus. Os linfócitos esféricos e de tamanho variável, com citoplasma escasso e ligeiramente basófilo, foram também descritos por Srivastava ${ }^{2 h}$ (1968) em qualro lipos de teleósteos. Os monócitos apresentaram-se predominantemente esféricos e com contorno irregular, e sua morfologia confir ma os achados de Srivastava ${ }^{26}$ (1958) e Ezzal et al. ${ }^{8}$ (1974). Em relação ao valor médio deste tipo celular deve ser ressaltado que se assemelhou ao encontrado por Ezzat el al ${ }^{x}(1974)$, sendo, no entanto, inferior numericamente ao demonstrado por Srivastava ${ }^{26}$ (1968), ao estudarem peixes de espécies diferentes de teleósteos.

Quanto aos trombócitos de Oreochromis niloticus, que se mostraram elípticos, com núcleo também elíptico, tiveram morfologia que não difere daquela encontrada por Doggelt; Harris" (1989) em Oreochromis mossambicus. Considerando- 
UEDA, I.K.: ECAMI, M.I.: SASSO, W.S.; MATUSHIMA, E.R. Esitudos homatológicos em Oreochromis niloticus (Linnaeus, 1758) (Cichlidae, Teleostei) - Parle I. Braz. J. vet. Res. anim. Sci., São Paulo, v. 34, 11. 5, p 270-275, 1997

se as grandes variações numéricas existentes relatadas na literatura sobre hematologia de peixes em geral, a contagem média global de trombócitos de Oreochromis niloticus difere daquela de Imagawa et al. ${ }^{44}$ (1989), que obtiveram valores menores. Tal disparidade de resultado estaria relacionada à dificuldade no diagnóstico morfológico diferencial entre alguns trombócitos e pequenos linfócitos esféricos. Essas células, apesar de semelhantes, apresentam pequena diferença no grau de condensação do material nuclear maior nos linfócitos e na coloração do citoplasma.

Assim sendo, considerando-se os resultados obtidos com a avaliação no sangue periférico de Oreochromis niloticus. pode-se contribuir com o estabelecimento de valores de referencia do hemograma e das características morfológicas das células sangüineas nesta espécie de teleósteo.

\section{SUMMARY}

Hemogram and cell morphology of peripheric blood samples obtained from 10 Oreochromis niloticus fishes have been evaluated. Some of these samples have been used in the accomplishment of hematimetry: eritrocytes count $\bar{x}=2.35 x$ $\left.10^{6} / \mathrm{mm}^{3} \pm 0.12\right)$, hemoblobin rate $(\bar{x}=7.04 \mathrm{~g} / \mathrm{dL} \pm 0.38)$, hematocrit $(\bar{x}=27.85 \% \pm 1.62), \mathrm{MHC}(\bar{x}=30.31 \mathrm{pg} \pm 1.64)$, $\operatorname{MCV}\left(\bar{x}=118.6 \mu^{3} \pm 3.53\right), \operatorname{MCHC}(\bar{x}=25.78 \% \pm 1.72)$, total leucocytes count $\left(\bar{x}=16.08 \times 10^{3} / \mathrm{mm}^{3} \pm 1.28\right)$, trombocytes count $\left(\bar{x}=61.69 \times 10^{3} / \mathrm{mm}^{3} \pm 5.96\right)$. Morphological evaluation of blood cells was performed by means blood smears extension submitted to Wright staining. Both nucleated eritrocytes and trombocytes presented an elliptical shape; neutrophiles and eosinophiles were spherical with spherical nucleus presenting different sizes, they also showed profuse citoplasms which were slightly basophilic and highly acidophilous, respectively. Polimorphonuclear shapes in these cells have not been verified Basophiles have shown spherical nucleus and metachromic granulations. Monocytes as well as lymphocytes resembled morphologically those of mammals.

\section{UNITERMS: Blood; Morphology; Hematology; Oreochromis niloticus; Fishes.}

\section{REFERÊNCIAS BIBLIOGRÁFICAS}

1 - BADAWI, H. K.; SAID, M. M. A comparative study of the blood of four Tilapia species (Pisces). Marine Biology, v. 8, n. 3, p. 202-4, 1971.

2 - BLACK. E C.; TUCKER. H. H.; KIRKPATRICK, D. The effect of hemolysis upon the oxygen affinity of hemoglobin in the Allantic (Salmo salar) and landlocked salmon (Salmo salar sebago). Journal of the Fisheries Research Board of Canada, v. 23, n.10, p. 1575-1780, 1966

3 - BLAXHALL, P.C.; DAISLEY, K. W. Routine haematological methods for use with fish blood. Journal of Fish Biology, v. 5, n. 6, p. 77I-81, 1973.

4 - BOOMKER, J. The haemocytology and histology of the haemopoetic organs of South African freshwater fish. III. The Leucocytes, plasma cells and macrophages of Clarias gariepinus and Sarotherodon mossambicus Onderstepoort. Journal of Veterinary Research. v. 48, n. 4, p. 185-93, 1981

5- CATTON, W. T. Blood cell formation in certain Teleost fishes. Blood, v. 6, n. I, p. $39-60,1951$

6-DOGGITT, T. A.; HARRIS. J. E. Ulirastructure of the peripheral blood leucocyles of Oreochromis mossambicus. Journal of Fish Biology, v. 34, n. 5, p. 747 56. 1989.

7 - ELI.IS, A. E. Leucocytes and related cells in the plaice Pleuronectes platessa. Journal of Fish Biology, v. 8, n. 2, p. 143-56, 1976

8- EZZAT, A. A.; SHABANA, M. B.; FARGHALY, A. M. Studies on the hlood characteristics of Tilapia zilli (Gervais). I. Blood cells. Journal of Fish Biology, v. 6, n. I, p. 1-12, 1974

9. FACCHINI, B. H. Estudos hematológicos sobre Mugil liza Cuvier \& Valenciennes e Mugil curema Cuvier \& Valenciennes da região estuariano lagunar de Cananéia. $25^{\circ}$ 1' S. Brasil. São Paulo, Instituto de Biociências, Universidade de São Paulo, 1987. 159 p. Dissertação (Mestrado)

10 - FERGUSON, H. W. The ultrastructure of plaice (Pleuronectes platessa) leucocytes. Journal of Fish Biology, v. 8, n. 2, p. 139-42, 1976.

11 - FLETCHER, G. L. The effects of capture "stress", and storage of whole blood cells plasma, proteins, glucose and electrolytes of the winter flounder (Pseudopleuronectes americanus). Canadian Journal of Zoology, v.53, $\mathrm{n}$. 2, p. 197-206, 1975

12 - HENDRICKS, L. J. Erythrocyte counts and hemoglobin determinations for two species of suckers, genus Catostomus, from Colorado. Copeia, v. 1, n. 4 , p. 265-6, 1952

13 - HOUSTON, A. H.; MADDEN, J. A.; WOODS, R. J.; MILES, H. M. Some physiological effects of handling and tricaine methanesulphonate anesthetization upon the brook trout, Salvelinus fontinalis. Journal of the Fisheries Research Board of Canada, v. 28, n. 4, p. 625-33, 1971

14 - IMAGAWA, T.; HASHIMOTO, Y.; KITAGAWA, H,; KON, Y.; KUDO, N.: SUGIMURA, M. Morphology of blood cells in carp (Cyprinus carpio L.) Japanese Journal of Veterinary Science, v. 51, n. 6, p. 1163-2, 1989.

15 - JAKOWSKA, S. Morphologie et nomenclature des cellules du sang des téléostécns. Revue d'Hematologie, v. 11, p. 519-39, 1956.

16 - JANNINI, P.; JANNINI FILHO, P. Interpretação clínica do hemograma. São Paulo, Sarvier, 1978. p. 109-111.

17 - KOUMANS-van-DIEPEN, J. C. E.; HARMSEN, E. G. M.; ROMBOUT, J. H W. M. Immunocylochemical analysis of mitogen reponses of carp (Cyprinus (arpio $L_{\text {. }}$ ) peripheral blood leucocytes. Veterinary Immunology and Immunopathology, v.42, n. 2, p. 209-19,1994

18 - MARTINS, J. M.; PITOMBEIRA, M. S. High leukocyle count in fishes. Revista Brasileira de Pesquisas Médicas e Biológicas, v. I, n. 2, p. 89-92, 1968

19 - MATUShimA, E. R. Cinética da reação inflamatória induzida pela carragenina na bexiga natatória de Oreochromis niloticus (Tilápia do Nilo). São Paulo, 1988.53 p. Dissertação (Mestrado). Faculdade de Medicina Veterinária e Zootecnia da Universidade de São Paulo.

20 - NAKAMO'TO, W.: SILVA, A. J.: MACHADO, P. E. A.; PADOVANI, C. R. SILVA, A. J.; MACHADO, E. A. Leukocyles and Curilia gomesi (blood parasite) in Synbranchus marmoratus Bloch, 1975 (Pisces, Symbranchidae) from the Birigui region of São Paulo. |Brazill. Revista Brasileira de Biologia, v. 51, n. 4, p. 755-61, 1992

2I - OLADIMEJI, A. A.: AYANTOYE. A. A.: ESIEVO, K. A. N. Hacmatological differences between two tropical freshwater fishes, Oreochromis niloticus and Clarias lazera. Revue de Zoologie Africaine, v. 102, p. 487-92, 1988.

22 - ORIA, J. Elementos figurados do sangue de alguns Teleósteos thuviais brasilejros (Nematognathas, characideos, Gymnotideos, Poecilideos). I. Erythrocytos: formas normaes, formas jovens e formas involuídas. Anais da Faculdade de Medicina da Universidade de São Paulo. v. 8, n. 1, p. 43-68, 1932.

23 - PHILLIPS JR. A. M. The development of anemia in trout fed a synthetic diet and its cure by the feeding of fresh beef liver. The Progressive Fish Culturist. v. 48, n. 1, p. $11-13,1940$. 
UEDA. I.K.; EGAMI, M.I.; SASSO. W S.: MATUSHIMA, E.R. Estudos hematológicos em Oreochromis niloticus (Linnaeus, 1758) (Cichlidae, Teleostei) - Päre I. Braz. J. vet. Res. anim. Sci., São Paulo, v. 34, n. 5. p. - -70-275, 1997

24 - QUENTEL, C.; OBACH, A. The cellular composition of the blood and hacmatopoetic organs of turbot Scophthalmus maximus L. Journal of Fish Biology, v. 41, n. 5, p. 709-716, 1992.

25 - RIBEIRO, W. R. Contribuição ao estudo da hematologia de peixes. Morfologia e citoquímica das células do sangue e dos tecidos hematopoéticos do mandí amarelo, Pimelodus maculalus Lacépède, 1803. Ribeirão Preto, 1978. $110 \mathrm{p}$ Tese (Doutorado). Faculdade de Medicina de Ribeirão Preto, Universidade de São Paulo.

26 - SRIVASTAVA, A. K. Studies on the haemalology of certain freshwater teleosts. IV. Leucocytes. Anatomischer Anzeiger, v. 123, p. 520-33, 1968.

Recebido para publicação: $\quad$ 14/8/95 Aprovado para publicação: 8/1 1/96 